\title{
EAMR
}

European Accounting and

Management Review

EUROPEAN ACCOUNTING AND MANAGEMENT REVIEW · VOL. 2, NO. 2, 56-76 MAY 2016

\section{Firm valuation and default probability through exotic (barrier) options}

\author{
Gaston Milanesi \\ Universidad Nacional del Sur \\ Gabriela Pesce \\ Universidad Nacional del Sur \\ Emilio El Alabi \\ Universidad Nacional del Sur
}

Received April 11, 2016; accepted May 23, 2016.

\begin{abstract}
Real option theory allows using financial option models to value investments and firms. Traditional models present a substantial problem to positively correlate underlying asset volatility with firm value. Therefore, an alternative approach is used based on a particular type of exotic option, the barrier one. This dynamic model helps estimating default probability incorporating the negative impact that excessive risk has on firm value. The article presents a hypothetical example illustrating similarities and differences between the proposed model and the traditional version. Finally, this model is applied on two of the leading companies in the Argentinean capital market which are characterized by different levels of leverage demonstrating the robustness of the results. The predicted default probability increases with the rise in assets volatility and the time horizon of debt maturity.
\end{abstract}

\section{KEYWORDS}

Default probability, firm valuation, barrier option, volatility, credit risk, call option. 


\section{Introduction}

In financial theory, the application of financial option theory on valuing real assets through its seminal models (Black \& Scholes, 1972) (Black \& Scholes, 1973) (Merton, 1973) has gained relevance. This group, known as real options, is integrated by a rich family of models. Its main advantage, compared to traditional models, is its capability of replicating and considering the complexity, dynamic, and strategic flexibility that explain firm value ${ }^{1}$. These valuation models, where option theory replicates strategic flexibility, consists in imitating the company's equity as a call option.

This concept was developed by Merton (1974), and originates several models used in predicting financial failures ${ }^{2}$. The logic behind this assumption is: firm equity $(E)$ is similar to a European call option that shareholders have over a leverage company value $(V)$ which is normally distributed. Classic financial sources play the following roles: debt as the exercise price and shareholders' equity as the consequent call option value. Related to liabilities, it is assumed a stated and unique expiration date. This implies that firm debt is similar to a zero coupon bond, with nominal value $(F)$, and stated expiration date $(T)$. Firm assets play as the underlying guarantying debt payments under the premise that shareholders could not force the company to break until the expiration date $(T)$. At expiration, when debt payment could be required, owners are exposed to two different scenarios: a) leverage assets exceed debt, so owners exercise the option paying debt and holding the difference; b) firm value is lower than debt, default is active, and the call is out-of-the-money. Thus, it is stated that terminal value is related to owners' wealth on each scenario as $E=\operatorname{MAX}[0,(V-F)]$. Applying call-put parity $V+p=F+E$ and rewriting the formula to leverage assets, we obtain the following parity $V=(F-p)+$ $E$. On the previous expression, leverage assets are divided between: equity $(E)$ and risky debt $(F-p)$. The position on equity is equivalent to a call option, while risky debt is equivalent to risk free present value $(F)$ minus a European put call $(p)$ over firm assets.

1 The advantages of real option models compared to classic valuation models as the discounted cash flow, residual income, multiples could be found in Dixit \& Pindyck (1994), Copeland \& Antikarov (2001) Mun (2004), Smith \& Trigeorgis (2004), Kodukula \& Chandra (2006). A classification of different real option models as continuous or discrete, fuzzy or probabilistic could be found in Milanesi (2013).

2 Among financial failure models, we could find structural models as the Z-score (Altman, 1968, 1993), (Altman \& Kishore, 1996), and dynamic models, based on market measures and contingent payment theory (Merton, 1974), (Varisek, 2001), (Crosbie \& Bohn, 2002), (Brockman \& Turtle, 2003), Hillegeist et al., 2004), (Reisz \& Perlich, 2007), (Bharath \& Shumay, 2008). 
The value at expiration for shareholders is $F-p=\operatorname{MIN}[V, F]$. Following previous ideas, at expiration, firm value is divided to satisfy obligations on lenders: creditors and shareholders. If we get a result where $V \geq F$, creditors get a payment worth their credit $(F)$, and the put option $(p)$ that they hold over the firm expires. On the contrary, if firm defaults, the put option gets active since the difference between debt and assets market value is lost. In other words, the option holder has the right to get $(F)$ but losses the positive differential $(V-F)$, being a payment until $V$, assets market value for the negative scenario.

Nonetheless, the fact that a company functioning could be similar to a European option has an important weakness because the value of a simple put/call option presents a strictly positive relationship with the underlying asset volatility. If this idea extrapolates to the logic of a company, agency problems could be presented (Jensen \& Meckling, 1976). On this line of thought, it could be argued that with the main objective of maximizing shareholders' wealth, managers might get on investments with growing risk, justifying that the higher the volatility, the bigger firm equity because it is similar to a call option. This behavior could lead to harm shareholders and creditors' interests.

Based on the previously exposed, this paper focuses on two objectives: a) proposing a dynamic model to estimating financial failures that predicts default probabilities incorporating the negative impact on firm value by taking excessive risk; b) implementing this model to an application case in order to manage the required entry variables and to demonstrate results' robustness.

Thus, two proposals from financial literature are combined: On the one hand, shareholders' equity is adapted to an exotic barrier option type knock out, down, and out call, following Reisz and Perlich (2007). On the other hand, to make this paper more applicable, model variables as volatility and asset firm value are estimated by taking the operative or naïve mode proposed by Bharath and Shumay (2008).

This work is structured in the following manner: on the next section, it is described the mathematical structure of the financial failure prediction based on barriers. It adopts a naïve conception related to volatility and asset value. On the third section, it is illustrated, through a hypothetical example, differences and similarities between the proposed model and the traditional version from Black and Scholes (1973) and Merton (1974). On the fourth section, the model is applied on two of the most relevant companies of the Argentinean capital market which are characterized by their different leverage level. This 
shows the robustness of the results related to the companies' fundamentals. Finally, a discussion and main conclusions are developed.

\section{Default prediction: exotic barrier options on their naïve version}

Throughout their work, Bharath and Shumay (2008) prove that Merton structural functioning $\operatorname{model}^{3}$ (Merton, 1974) is effective in default prediction. However, they tested a simplified version known as naïve. In contrast to Merton's model, this version tries not to solve two no linear equations simultaneously to infer volatility and assets intrinsic value $^{4}$. Firm asset value, magnitude that it is impossible to determine from market prices, is replaced by its liabilities plus its market capitalization. The second variable, risk or asset volatility, is substituted by an operative version of volatility obtained from unleveraged equity (Schwert, 1989; Daouk \& Ng, 2011). The naïve version's predictive capacity is pretty similar to Merton model according to the results of Bharath and Shumay (2008); adding simplicity while implementing (Chen \& So, 2014).

The structural functioning of equations that estimate equity comes out of describing it as a call option, according to equations 1 and 2 .

$c=(E+F) e^{-q(T-t)} N\left(d_{1}\right)-F e^{-r(T-t)} N\left(d_{2}\right)$ (Eq. 1)

$p=(E+F) e^{-q(T-t)} N\left(-d_{1}\right)+F e^{-r(T-t)} N\left(-d_{2}\right)$ (Eq. 2)

Shareholders' equity market value plus liabilities accounting value $(E+F)$ represents asset value at the time of valuing it, being $V=E+F$. As it was indicated, liabilities are similar to a zero coupon bond with expiration date $T$.

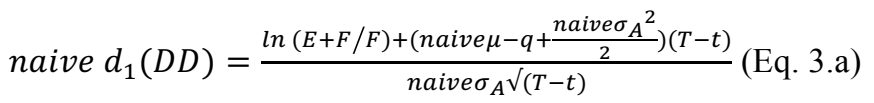

3 The model estimated default distance known as DD and insolvency probability.

4 The model begins by considering firm's capital as an eueopean call option, set as a five equation system:

1) $\mathrm{E}=\mathrm{VN}\left(\mathrm{d}_{1}\right)-\mathrm{Fe}^{-\mathrm{r}(\mathrm{T}-\mathrm{t})} \mathrm{N}\left(\mathrm{d}_{2}\right)$ where $V$ represents assets value assumed to follow a stochastic Brownian geometric process (GBM), $F$ represents liabilities value and $N($.) accumulated standard normal distribution; 2) $\mathrm{d}_{1}=\frac{\ln (\mathrm{V} / \mathrm{F})+\left(\mathrm{r}+\frac{\sigma_{\mathrm{A}}^{2}}{2}\right)(\mathrm{T}-\mathrm{t})}{\sigma_{\mathrm{A}} \sqrt{(\mathrm{T}-\mathrm{t})}}$; and 3$) \mathrm{d}_{2}=\mathrm{d}_{1}-\sigma_{\mathrm{A}} \sqrt{(\mathrm{T}-\mathrm{t})}$. Moreover, two more simultaneous equations are necessary to assign value to two variables that market does not value directly. They value assets using a GBM process. 4) $d V / V=\mu d t+\sigma_{a} d B$ and its volatility; 5) $\sigma_{e} E=(\partial E / \partial V) \sigma_{v} V=N\left(d_{1}\right) \sigma_{v} V$ where $\sigma_{E}$ is stock volatility, Solving this five equation system, distance and default probability are obtained $\pi_{\text {Merton }}=N\left(-d_{2}\right)=N(-$ Merton DD $)($ Chen \& So, 2014). Bharath and Shumay (2008) demonstrate that the prediction power of this model is equivalent to its proposal. The latter one is simpler computational wise, and it incorporates all variables that generate value to the firm. 
naive $d_{2}=d_{1}-$ naive $_{A} \sqrt{ }(T-t)$ (Eq. 3.b)

On this model, $r$ is the risk free rate, and $\mu$ is the return for shareholders the previous year (Equation 3.a). Asset volatility $\left(\sigma_{A}\right)$ comes out of unlevereging observed volatility or implicit in shareholders' equity, $\sigma_{A}=\sigma_{E} \frac{E}{E+F}$. Default distance $(D D)$ (Equation 3.a) comes out of the difference between firm value and liabilities divided by standard deviation. Naïve default probability is presented on Equation $4^{5}$. $\pi^{\text {naive }}=\mathrm{N}\left(-\right.$ naive $\left.\mathrm{d}_{1}(\mathrm{DD})\right)$ (Eq. 4).

A model that explains functional logic of Merton but adjusts capital value while having increments in volatility, thus business risk, requires to add the logic of a knock out, down, and out call option adapted to the naïve model. Following Brockman and Turtle (2003), and Reisz and Perlich (2007), a traditional call option is equal to the sum of down and out call, and down and in call (Hull, 2005; Gaarder, 2007) ${ }^{6}$.

It is necessary a model that corrects the equity value while having increments in risk, and having this situation reflected in higher default probabilities. Instead of considering shareholders' equity as a classic call option, it is proposed to treat it as an exotic barrier option as knock out, similar to a down and out call. Barrier options are those which value is conditioned to the fact that the underlying reaches a determined level or barrier $(B)$ established during the life of the contract. In general, prime is lower than the typical

\footnotetext{
${ }^{5}$ The cash flow of a call option at expiration is equal to $c_{t}=\operatorname{Max}\left(S_{t}-X ; 0\right)$. It could be desegregated in two different components. The first component represents exercise price payment conditioned to the option to be exercised $c_{t}^{1}=-X$ if $S_{t} \geq X$. The second component represents the acquisition of the underlying assets as long as the option ends up in-the-money $c_{t}^{2}=S_{t}$ if $S_{t} \geq X$. Both are contingent payments (conditioned) that the option finishes in-the-money. Contingent exercise price present value is equal to the expected future price adjusted by neutral probability of exercise, to the discounted risk at the risk free rate $c_{t}^{1}=-X e^{-r t} P\left(S_{t} \geq X\right)$. The probability that the options finishes in-the-money at expiration is $X P\left(S_{t} \geq X\right)=N\left(d_{2}\right)$, being the expected discounted value $-X e^{-r t} N\left(d_{2}\right)$, being the first component of the option present value. The second component, the expected payment present value at expiration is equal to the underlying expected price from the exercised price times the probability of exercising the option $c_{t}^{2}=E\left\{S_{t}\left|S_{t}>X\right|\right\} P\left\{S_{t}>X\right\}=e^{-r t} S N\left(d_{1}\right)$. Out of this conclusion, temporal value is explained, and how it is higher than the intrinsic value. Consequently, $\pi^{\text {naive }}=N\left(-d_{1}(D D)\right)$, could be intrepreted as its complement. In other words, the probability that underlying expected value conditioned to the noexercise is not higher than liabilities value (default probability). A more deeper analysis related to coefficients $N\left(d_{1}\right)$ and $N\left(d_{2}\right)$ could be found in Nielsen (1992).

${ }^{6}$ If the barrier options profiles are added as in knock out, it is observed that when one of the option expires, the other one gets active. Therefore, the result is the one of a regular call.
} 
vanilla option, and they are grouped in two different classes: knock out option $(\mathrm{koo})$ and knock in options (kio). The former stops existing when the underlying reaches the defined barrier. The latter starts existing once this level is reached ${ }^{7}$.

In practice, anticipating to a potential default given a level of debt implies to define a barrier which is, in general, lower or equal to debt value taken by the firm. Under this logic, shareholders' equity could be estimated by using this type of options. Once the barrier $(B)$ is defined for liabilities that are lower or equal to it, $B \leq F$, it is required to determine the option being a down and out call. Its value comes out of the difference between a regular call (Equation 1) and a down and in call (dic). A dic expression is presented on equation 5 .

dic $=(E+F) e^{-q(T-t)}(B /(E+F))^{2 \lambda} N(y)-F e^{-r(T-t)}(B /(E+F))^{2 \lambda-2} N\left(y-\right.$ naive $\left._{A} \sqrt{ }(T-t)\right)$

(Eq. 4)

$\lambda=\frac{\mu-q+\text { naive }_{A}{ }^{2} / 2}{{\text { naive } \sigma_{A}{ }^{2}}^{2}}($ Eq. 5)

$y=\frac{\ln \left(B^{2} /(E+F) \times F\right)}{\text { naive }_{A} \sqrt{ }(T-t)}+\lambda$ naive $_{A} \sqrt{ }(T-t)($ Eq. 6)

Therefore, $d o c=c-d i c($ Hull, 2005).

Less frequent but possible, in particular for firms with low level of leverage, barriers could be settled for levels higher than the liabilities $B>F$. On these cases, the barrier option to use belongs to a down and out call ( $d o c)$ (Equation 8).

$d o c=(E+F) e^{-q(T-t)} N\left(x_{1}\right)-F e^{-r(T-t)} N\left(x_{1}-\right.$ naive $\left._{A} \sqrt{T-t}\right)-(E+$

$F) e^{-q(T-t)}(B /(E+F))^{2 \lambda} N\left(y_{1}\right)+F e^{-r(T-t)}(B /(E+F))^{2 \lambda-2} N\left(y_{1}-\right.$ naive $\left._{A} \sqrt{ }(T-t)\right)$ (Eq. 7)

$x_{1}=\frac{\ln (E+F / B)}{\text { naive }_{A} \sqrt{ }(T-t)}+\lambda$ naive $\sigma_{A} \sqrt{ }(T-t)($ Eq. 8$)$

$y_{1}=\frac{\ln (B / E+F)}{\sigma_{A} \sqrt{ }(T-t)}+\lambda \sigma_{A} \sqrt{ }(T-t)($ Eq. 9)

On the traditional financial default model proposed by Bharath and Shumay (2008), default probability at expiration is given by Equation 4 .

$\left(\pi^{\text {naive }}(E+F)_{T}<F\right)=N\left(-\right.$ naive $\left.d_{1}(D D)\right)($ Eq. 10)

\footnotetext{
${ }^{7}$ Call and put options kio are: a) down and in call and put (cdi, pdi) that start existing when the underlying is below $B$; b) up and in call and put (cui, pui) start existing when the option is higher than $B$. Call and put option koo are: a) down and out call and put ( $c d o, p d o$ ) stop existing when the underlying reaches $B$; b) up and out call and put (cud, pud) stop existing when the underlying is higher than $B$. It is important to mention that when the value of $B$ is higher or equal to the exercise price, the value of $c u o$ is zero and the value of $c u i$ is $c$, and $c d o$ and $c d i$ have a price indistinctly $B$ being higher, lower, or equal than the exercise price. Continuing with the same logic, when the barrier is higher than the exercise price, then $p d o$ does not have value and $p d i$ assumes value $p$, when $p u i$ and $p u d$ have price indistinctly as the manner of the barrier being arranged in relation with the exercise price.
} 
Traditional version only takes into consideration the case where, at expiration $(T)$, the value of assets is lower than liabilities without considering debt levels. This also occurs on any European call option.

Following Reisz and Perlich (2007), in case of defining debt level below $B \leq F$, authors propose a series of expressions to estimate default probability. As it will be exposed, as asset volatility is higher (business risk), default probabilities are higher, as well. This is something that it is not seen on the Merton's adapted naïve version. Default probability could be separated in a function with two temporal states: a) default probability before expiration; b) default probability at expiration. It is adjusted to situations where the underlying asset (firm assets) is higher than the barrier (default state) but lower than liabilities. Therefore, at expiration, debt could be cancelled. Total default probability comes out of the sum of the two previous ones. Thus, the probability that the assets assume values below the barrier during a state previous to expiration, $\left(t^{*}\right)$, is determined by the following expression (Equation 12).

$P\left((E+F)_{t *<T}<B\right)=N\left[\frac{\ln (B /(E+F))+\left(\mu-q+\frac{\text { naive }_{A}^{2}}{2}\right)(T-t)}{\text { aive }_{A} \sqrt{T-t}}\right]+$
$(B /(E+F))^{\left[2(\mu-q) / \text { naive }_{A}^{2}\right]-1} N\left[\frac{\ln (B /(E+F))+\left(\mu-q+\frac{\text { naive }_{A}^{2}}{2}\right)(T-t)}{\text { naiver }_{A} \sqrt{T-t}}\right]$ (Eq. 11)

The second case occurs when, at expiration, assets value is higher than the level of insolvency but high enough to cancel liabilities. On these cases, default probability is estimated through Equation 13.

$$
\begin{aligned}
& P\left(B<(E+F)_{T}<F\right)=N\left[\frac{\ln ((E+F) / B)+\left(\mu-q+\frac{\text { naive }_{A}{ }^{2}}{2}\right)(T-t)}{\text { naive }_{A} \sqrt{T-t}}\right]-N\left[\frac{\ln ((E+F) / F)+\left(\mu-q+\frac{\text { naive }_{A}^{2}}{2}\right)(T-t)}{\text { naive }_{A} \sqrt{T-t}}\right]- \\
& (B /(E+F))^{\left[2(\mu-q) / \text { naive }_{A}^{2}\right]-1} N\left[\frac{\ln (B /(E+F))+\left(\mu-q+\frac{\text { naive }_{A}^{2}}{2}\right)(T-t)}{\text { naive } \sigma_{A} \sqrt{T-t}}\right]- \\
& N\left[\frac{\ln \left(B^{2} /(E+F) F\right)+\left(\mu-q+\frac{\text { naive }_{A}^{2}}{2}\right)(T-t)}{\text { naive }_{A} \sqrt{T-t}}\right] \text { (Eq. 12) }
\end{aligned}
$$

Total default probability, before and at expiration, is the sum of Equations 12 and $13^{8}$. This paper proposes to adapt Reisz and Perlich (2007) model to a naïve version, measuring value and asset volatility by the previously described manner.

\footnotetext{
${ }^{8}$ In cases where $\mathrm{B} \geq \mathrm{F}$ Equation 11 applies directly, then traditional Merton model, being these probabilities, default probabilities. This occurs because it is measured the probabilities that assets being lower than $F$ since $B$ is settled higher than liabilities.
} 


\section{Model functioning from a hypothetical case}

On this section, it is presented a hypothetical case in order to illustrate model functioning developed during the preceding section. Then, it will be applied on two firms that operate on the Argentinean capital market. On this example, it is assumed a firm with asset value $(V)$ of $\$ 100$, liabilities $(F)$ of $\$ 80$, and shareholders' equity $(E)$ of $\$ 20$. Assets rate of return $(\mu)$ is $10 \%$ and dividends $(q)$ are $3 \%$ annually. Asset volatility is given, and it is $30 \%$. Finally, risk free rate is $5 \%$ a year, and liabilities' payment structure is similar to a zero coupon rate with expiration $(T)$ in 10 years. It is established an insolvency barrier $(B)$ of $70 \%$ of total assets. When the value of assets reaches that level, in other words, when it goes down, insolvency is active. It must be highlighted that the barrier level fixed is lower than the company's leverage that, in this case, rises up to $80 \%$.

After the preceding data, shareholders' equity must be calculated using the traditional model (Equation 1). This rises to $\$ 34.98$ and default probability (Equation 4) is $32.35 \%$. Next, Table 1 is presented where a bivariated sensitivity analysis relative to default probability is exposed (Equation 4). Two variables are modified: a) assets volatility $\left(\sigma_{a}\right)$; b) debt payment timing $(T)$.

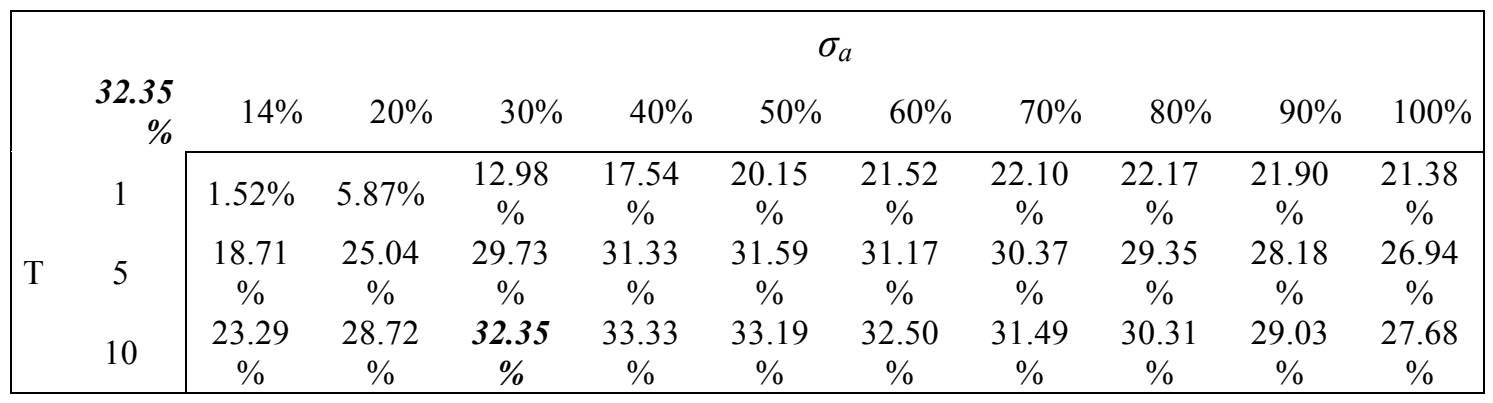

Table 1. Sensitivity of default probability related to assets' volatility and temporal horizon under the traditional option model. Source: Own elaboration.

Table 1 ratifies that the model developed in Equations 1 through 4 presents the typical behavior of a traditional call option. As volatility increases, in particular for values $>60 \%$, default probabilities decrease, as a result of a rise on the underlying expected value. The latter is explained by the increase of the probability of exercising the option $\left(N d_{2}\right)$ and the rise of the underlying expected value conditioned by the probability of exercising the option $\left(N d_{1}\right)$. Previous statement is consistent with the behavior related to $E$ since the higher the volatility, the higher its value and the lower the default probabilities, as it is exposed on Table 2. 


\begin{tabular}{|cccccccccccc|}
\hline \multicolumn{1}{|c}{} & \multicolumn{10}{c|}{$\sigma_{a}$} \\
& 34.98 & $14 \%$ & $20 \%$ & $30 \%$ & $40 \%$ & $50 \%$ & $60 \%$ & $70 \%$ & $80 \%$ & $90 \%$ & $100 \%$ \\
\cline { 2 - 12 } & 1 & 21.10 & 21.79 & 23.88 & 26.53 & 29.42 & 32.42 & 35.46 & 38.50 & 41.51 & 44.48 \\
$\mathrm{~T}$ & 5 & 25.26 & 27.80 & 32.76 & 37.82 & 42.59 & 46.94 & 50.80 & 54.18 & 57.10 & 59.61 \\
& 10 & 27.09 & 29.92 & 34.98 & 39.58 & 43.39 & 46.40 & 48.73 & 50.56 & 52.05 & 53.33 \\
\hline
\end{tabular}

Table 2. Sensitivity of option value related to assets' volatility and temporal horizon under the traditional option model. Source: Own elaboration.

On the traditional model, if the analyst is strictly adjusted to those results, he could conclude that the bigger the business risk, the higher the firm value. Therefore, it is recommended to incorporate projects that increment the company's portfolio risk. This situation could justify decisions against shareholders' interests.

Then, in order to solve this situation, it is applied the barrier option model. On this example, since it is $B<F$, first it is estimated a down and in call (dic) in through Equations 5, 6, and 7. Finally, shareholders' equity comes out from the difference between the European call (c) and the dic. Results are detailed on Table $3^{9}$.

\begin{tabular}{|lcr|}
\hline (eq.6) & $\lambda$ & 1.2778 \\
(eq.7) & $y$ & 0.6954 \\
(eq.5) & dic & $\$ 5.65$ \\
(eq.1) & $c$ & $\$ 34.98$ \\
\cline { 2 - 3 } & doc & $\$ \mathbf{2 9 . 3 2}$ \\
\hline
\end{tabular}

Table 3. Value $E$ according to barrier $d o c$ option. Source: Own elaboration.

As it was explained, the value of the $d o c$ is lightly inferior to a traditional call since the dic acts as an adjustment for levels where $B<V$.

Afterwards, default probabilities are estimated. Applying Equation 12, the probability that the underlying assumes values beneath the barrier during the life of the option $\left(t^{*}\right)$ is $47.55 \%$. The probability that, at expiration, the asset is higher than the barrier level $V>B$, but lower than liabilities $V<F$, and, thus, falls into default is equal to $16.15 \%$ (Equation 13). Consequently, total default probability (before and at expiration, even if

\footnotetext{
${ }^{9}$ The model is consistent since it must arrive to a similar adjusted conclusion over the value of the call (Eq. 1) by applying equations 8,9 , and 10 for the down and out call. On this case, $x_{l}$ (eq. 9) is $1.447 ; y_{1}$ (eq. 10) is 0.8362 , and finally $d o c$ value (eq. 8 ) is $\% 5.65$.
} 
assets are higher than the barrier but lower than liabilities) is $63.71 \%$. As it occurred on the previous case, Table 4 is presented as a result of the sensitivity analysis of the default probability (Equations 12 and 13 ) related to volatility $\left(\sigma_{a}\right)$ and debt payment moments.

\begin{tabular}{|cccccccccccc|}
\hline \multicolumn{1}{c}{} & \multicolumn{10}{c|}{$\sigma_{a}$} \\
\multicolumn{1}{c}{} & $\mathbf{6 3 . 7 1 \%}$ & $14 \%$ & $20 \%$ & $30 \%$ & $40 \%$ & $50 \%$ & $60 \%$ & $70 \%$ & $80 \%$ & $90 \%$ & $100 \%$ \\
\cline { 2 - 11 } & 1 & $2.2 \%$ & $9.2 \%$ & $25.4 \%$ & $40.7 \%$ & $53.0 \%$ & $62.2 \%$ & $69.3 \%$ & $74.8 \%$ & $79.1 \%$ & $82.5 \%$ \\
$\mathrm{~T}$ & 5 & $7.8 \%$ & $26.6 \%$ & $54.2 \%$ & $70.9 \%$ & $80.7 \%$ & $86.9 \%$ & $90.9 \%$ & $93.5 \%$ & $95.4 \%$ & $96.7 \%$ \\
& 10 & $9.8 \%$ & $33.4 \%$ & $\mathbf{6 3 . 7 \%}$ & $79.6 \%$ & $88.1 \%$ & $92.8 \%$ & $95.6 \%$ & $97.3 \%$ & $98.3 \%$ & $99.0 \%$ \\
\hline
\end{tabular}

Table 4. Sensitivity of the default probability related to asset volatility and temporal horizon under the barrier option model. Source: Own elaboration.

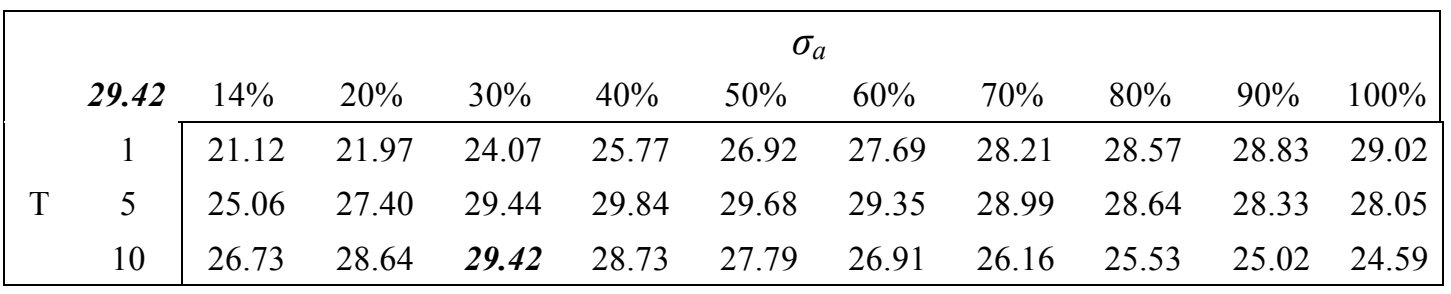

Table 5. Sensitivity of the default probability related to asset volatility and temporal horizon under the barrier option model. Source: Own elaboration.

These preceding tables demonstrate how the model adjusts to the business logic since excessive risk levels are against value. Agents recognized that the company is highly risky and has high probabilities of having financial difficulties. On this example, for assets volatility levels $>60 \%$, value $E$ diminishes as a consequence of an increment of the firm default probabilities ${ }^{10}$.

Through a graphical analysis (Figures 1, 2, and 3), it is observed how default probabilities grow while facing increments in assets volatility and temporal horizon while using a barrier model (Figure 2). This is contrary to the probability behavior under a traditional option model (Figure 1). The logic behind obtaining the company value generates equilibrium between managers' decisions and firm value.

\footnotetext{
${ }^{10}$ For short peeriods of time $(t=1)$, shareholders' equity value does not decreas since volatility plays a more important role than time where the probabilities of the assets being beneath fixed liabilities is almost zero. These probabilities and their effect in value are presented from $t>1$.
} 


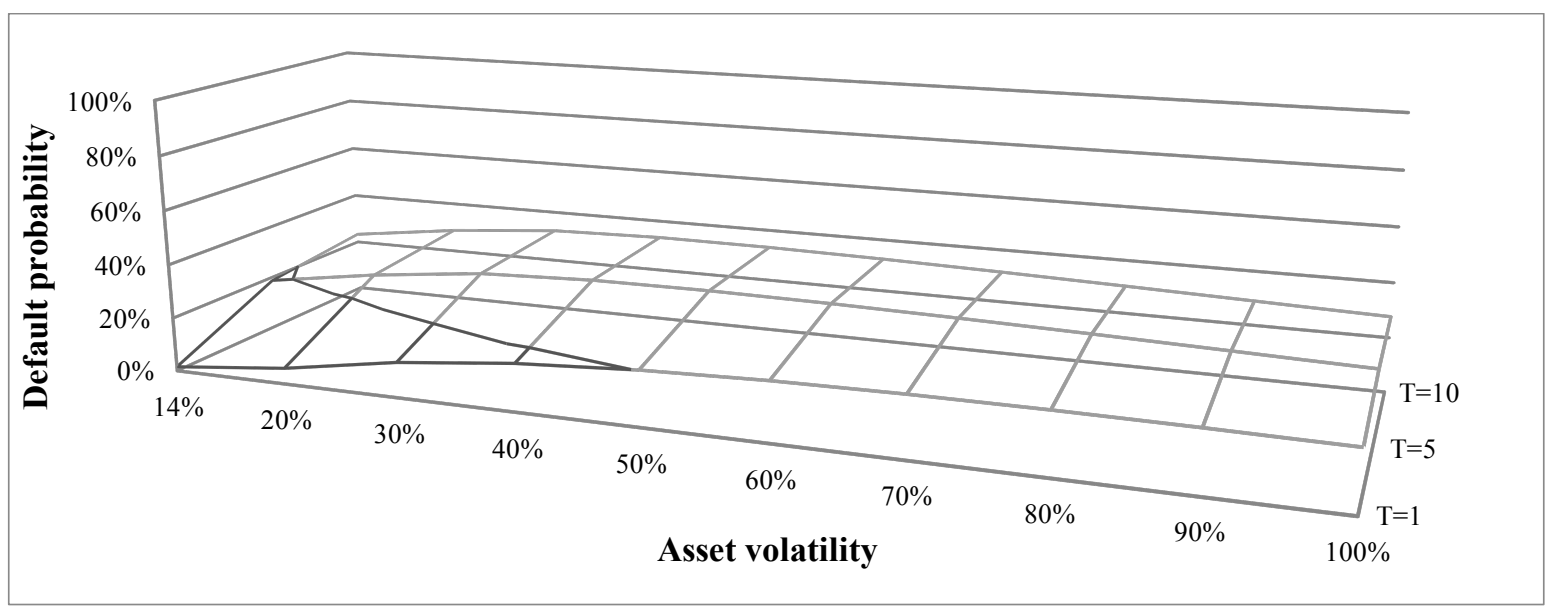

Figure 1. Default probability related to asset volatility and temporal horizon under the traditional model. Source: Own elaboration.

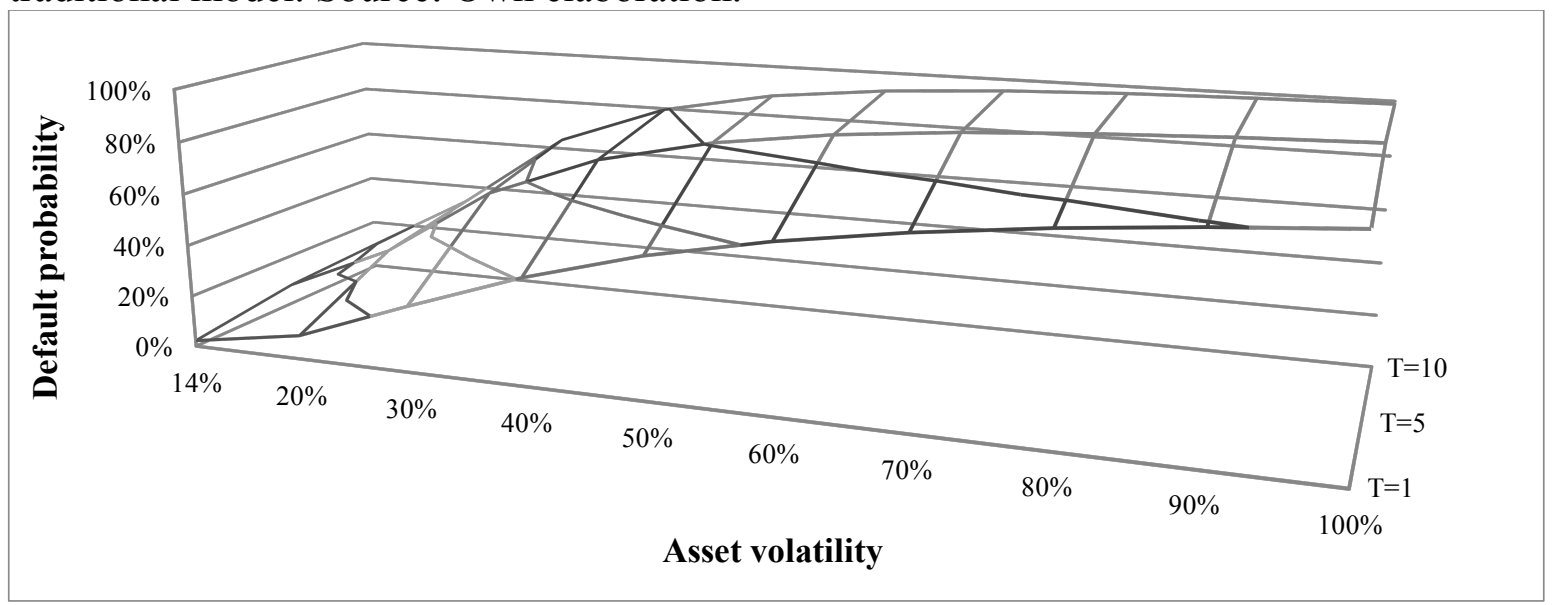

Figure 2. Default probability related to asset volatility and temporal horizon under the barrier option model. Source: Own elaboration.

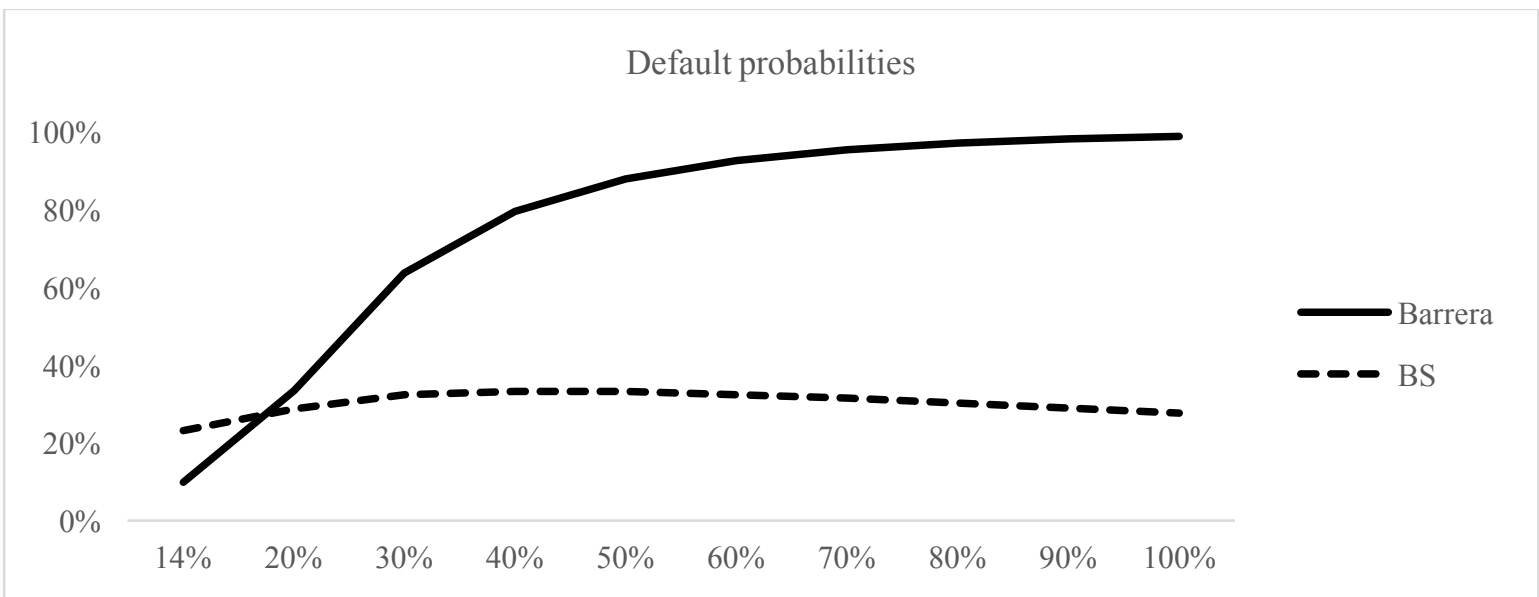

Figure 3. Default probability related to asset volatility under traditional and barrier options. Source: Own elaboration. 


\section{Model application on two argentinean cases: ypf and aluar}

Selected firms are: YPF, owned mainly by public capitals, which dedicates to exploring, exploiting, and refining oil; and ALUAR, owned by private capitals, is from the siderurgical industry. It is assumed that market capitalization is taken as equity $(E)$, and accounting liabilities informed to the demanded debt $(F)$ are similar to a zero coupon bond. Moreover, asset rate of return $(\mu)$ comes out of ROA. On this case, it is the division between the operative result after taxes and total assets. Dividends rate $(q)$ comes out of the division between dividends paid to shareholders during the period under study and the net result during the same period of time. Risk free rate is estimated from an American 10 -year T-bond yield at 1.75\% annually plus EMBI in Argentina which had 453 point representing $6.28 \%$ rate $^{11}$.

Afterwards, data related to the firms relevant variables at 12/30/15 are described. All data are in thousands of American dollars ${ }^{12}$. On YPF, market capitalization rises to $\$ 7,565,000$, total liabilities $(F)$ are $\$ 15,954,524$. Assets accounting value are $\$ 24,506,933$, ordinary results after taxes are $\$ 1,039,835$. The financial leverage relationship (F/E) is 1.87 and ordinary dividends ${ }^{13}$ have a mean during the 2006-2015 period of $\$ 898,495$, being $\$ 54,254$ in $2015^{14}$.

On ALUAR, market capitalization $(E)$ and liabilities $(F)$ rise to $\$ 1,879,000$ and $\$ 403,446$, respectively. Assets accounting value are $\$ 1,217,230$, and the ordinary result after taxes is $\$ 145,366$. The financial leverage relationship is 0.21 , and ordinary dividends have a mean during the 2006-2015 period of \$32,584, being \$14,108 in 2015.

Asset theoretical value $(V)$ and asset volatility $\sigma_{A}$ are two variables which cannot be observed straight from market prices. Asset theoretical value is calculated iterating using

\footnotetext{
${ }^{11}$ Source: http://www.ambito.com/economia/mercados/riesgo-pais/. 12

Source: https://orbis.bvdinfo.com/version2016219/Report.serv?_CID=529\&context=URULC763WYE9SOO\&Se $\mathrm{qNr}=0$.

13 \$1,619,000 (2006); \$775,000 (2007); \$0 (2008); \$2,705,000 (2009); \$1,295,000 (2010); \$1,123,000 (2011); \$1,299 (2012); \$61,826 (2013); \$50,146 (2014); \$54,254 (2015).

${ }^{14}$ It must be noticed that the firm used to pay dividends offshore to its shareholders until 2011. That's when the Argentinean government expropriate it.
} 
Equation 1 where restrictions are that the call is equal to market capitalization $(E)^{15}$. This implies that market values are an approximate measure of the real company's capital. Asset volatility was obtained using a simple method. Stock volatility is taken into account and, then, capital structure effect is taken away using the following expression: $\sigma_{A}=$ $\sigma_{E} \frac{E}{E+F}$ (Schwert, 1989).

On YPF, $V$ rises to $\$ 30,905,060.80$, and ALUAR presents an intrinsic asset value of $\$ 5,647,597.06$. Values related to principle variables are listed on Table 6.

\begin{tabular}{|ccc|ccc|}
\hline Variables & YPF & ALUAR & Variables & YPF & ALUAR \\
\hline $\boldsymbol{V}$ & $\$ 30,905,060,80$ & $\$ 5,647,597,06$ & $\boldsymbol{\Sigma}$ & $24.43 \%$ & $16.46 \%$ \\
$\boldsymbol{E}$ & $\$ 8,552,409,00$ & $\$ 1,879,000,00$ & $\boldsymbol{R}$ & $6.28 \%$ & $6.28 \%$ \\
$\boldsymbol{F}$ & $\$ 15,954,524,00$ & $\$ 403,446,00$ & $\boldsymbol{T}$ & 10 & 10 \\
Accounting assets & $\$ 24,506,933,00$ & $\$ 2,282,446,00$ & $\boldsymbol{B}$ & $\$ 11,168,166,80$ & $\$ 282,412,20$ \\
$\boldsymbol{\mu}$ & $5.82 \%$ & $11.90 \%$ & $\boldsymbol{Q}$ & $5.22 \%$ & $9.70 \%$ \\
\hline
\end{tabular}

Table 6. Selected company's data used for the analysis. Sources: Orbis and own elaboration.

On Tables 7, 8, 9, and 10 default probabilities and equity are estimated applying Merton's naïve version (1974). Tables 7 and 8 present sensitivity analyses related to firms default probabilities analyzed when having increments in volatility and temporal horizon.

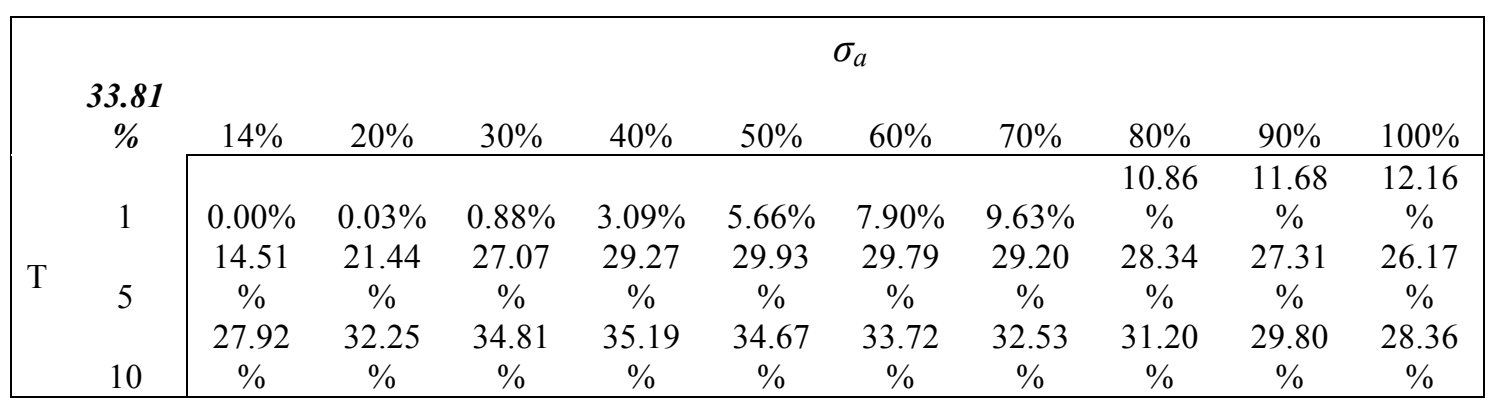

Table 7. YPF default probability sensitivity according to asset volatility and temporal horizon under the traditional option model. Source: Own elaboration.

\footnotetext{
${ }^{15}$ The procedure consists in introducing relative values to the rest of the variables and, through a iterative process, asset objective value is obtained. It must be used: Menu, data, and search objective on Microsoft Excel ${ }^{\circledR}$.
} 


\begin{tabular}{|c|c|c|c|c|c|c|c|c|c|c|c|}
\hline & \multicolumn{11}{|c|}{$\sigma_{a}$} \\
\hline & $3.44 \%$ & $14 \%$ & $20 \%$ & $30 \%$ & $40 \%$ & $50 \%$ & $60 \%$ & $70 \%$ & $80 \%$ & $90 \%$ & $100 \%$ \\
\hline \multirow{3}{*}{$\mathrm{T}$} & 1 & $0.00 \%$ & $0.00 \%$ & $0.00 \%$ & $0.00 \%$ & $0.00 \%$ & $0.00 \%$ & $0.00 \%$ & $0.01 \%$ & $0.03 \%$ & $0.08 \%$ \\
\hline & 5 & $0.00 \%$ & $0.22 \%$ & $2.37 \%$ & $5.77 \%$ & $8.86 \%$ & $11.19 \%$ & $12.81 \%$ & $13.85 \%$ & $14.44 \%$ & $14.69 \%$ \\
\hline & 10 & $1.73 \%$ & $6.31 \%$ & $13.50 \%$ & $18.02 \%$ & $20.56 \%$ & $21.87 \%$ & $22.41 \%$ & $22.44 \%$ & $22.13 \%$ & $21.60 \%$ \\
\hline
\end{tabular}

Table 8. ALUAR default probability sensitivity according to asset volatility and temporal horizon under the traditional option model. Source: Own elaboration.

While comparing results related to these firms, it can be observed that YPF presents a higher default probability than ALUAR. This result is consistent with company's fundamentals. YPF is emerging from a capital and debt restructuration process with a leverage ratio of 1.87 in $2015^{16}$. On the contrary, ALUAR is a company with stable capital structure and low leverage ratio. In fact, it is 0.21 . Nonetheless, on both cases, it is verified that as the business risk increases, default probabilities decrease because of the positive impact that volatility has on a European call. Again, this situation does not happen on real assets where higher volatility is translated as an increment in business risk explained by excessive operative leverage (fixed costs), market characteristics (low entry barriers and high exit barriers), obsolete technology, potential competitors and substitutes, etc.

\begin{tabular}{|c|c|c|c|c|c|c|c|c|c|c|}
\hline & \multicolumn{10}{|c|}{$\sigma_{a}$} \\
\hline & 9.060 & $14 \%$ & $20 \%$ & $30 \%$ & $40 \%$ & $50 \%$ & $60 \%$ & $70 \%$ & $80 \%$ & $90 \%$ \\
\hline \multirow{3}{*}{$\mathrm{T}$} & 1 & 14.350 & 14.350 & 14.377 & 14.508 & 14.775 & 15.155 & 15.619 & 16.141 & 16.699 \\
\hline & 5 & 11.357 & 11.306 & 11.814 & 12.601 & 13.452 & 14.282 & 15.055 & 15.755 & 16.380 \\
\hline & 10 & 8.479 & 8.747 & 9.499 & 10.283 & 10.979 & 11.561 & 12.040 & 12.440 & 12.786 \\
\hline
\end{tabular}

Table 9. YPF option value sensitivity related to asset volatility and temporal horizon under the traditional option model. Source: Own elaboration.

\begin{tabular}{|c|c|c|c|c|c|c|c|c|c|c|}
\hline & \multicolumn{10}{|c|}{$\sigma_{a}$} \\
\hline \multirow{4}{*}{$\mathrm{T}$} & 1.883 & $14 \%$ & $20 \%$ & $30 \%$ & $40 \%$ & $50 \%$ & $60 \%$ & $70 \%$ & $80 \%$ & $90 \%$ \\
\hline & 1 & 4.748 & 4.748 & 4.748 & 4.748 & 4.748 & 4.748 & 4.748 & 4.748 & 4.749 \\
\hline & 5 & 3.190 & 3.185 & 3.135 & 3.061 & 2.999 & 2.959 & 2.936 & 2.926 & 2.926 \\
\hline & 10 & 1.910 & 1.840 & 1.737 & 1.681 & 1.655 & 1.645 & 1.646 & 1.652 & 1.663 \\
\hline
\end{tabular}

Table 10. ALUAR option value sensitivity related to asset volatility and temporal horizon under the traditional option model. Source: Own elaboration.

\footnotetext{
${ }^{16}$ Leverage makes, quantitatively, the barrier higher which increases the probabilities of no-exercise of the option. An interest work is to determine correlation between leverage, solvency, and return considering default probabilities obtained in these models.
} 
At the same time, both companies' capital value, exposed on Tables 9 and 10, are correlated with default probabilities as volatility levels increase. Tables 11 and 12 present results related to equations used to estimate $d o c$.

\begin{tabular}{|ccc|}
\hline (eq.6) & $\lambda$ & 0.6007 \\
(eq.7) & $y$ & -1.3152 \\
(eq.5) & $d i c$ & $\$ 64,313.24$ \\
(eq.1) & $c$ & $\$ 9,060,924.42$ \\
\cline { 2 - 3 } & $\boldsymbol{d o c}$ & $\mathbf{\$ 8 , 9 9 6 , 6 1 1 . 1 7}$ \\
\hline
\end{tabular}

Table 10. YPF $E$ value under the doc barrier model. Source: Own elaboration.

\begin{tabular}{|ccc|}
\hline (eq.6) & $\lambda$ & 1.3115 \\
(eq.7) & $\mathrm{y}$ & -5.7556 \\
(eq.5) & dic & $-\$ 0.0001903$ \\
(eq.1) & $\mathrm{c}$ & $\mathbf{\$ 1 , 8 8 3 , 4 7 7 . 4 2}$ \\
\cline { 2 - 3 } & doc & $\mathbf{\$ 1 , 8 8 3 , 4 7 7 . 4 2}$ \\
\hline
\end{tabular}

Table 11. ALUAR $E$ value under the doc barrier model. Source: Own elaboration.

In contrast with Tables 7 and 8 , default probabilities increase as volatility levels rise. As it happened on the previous case, YPF has a higher default risk than ALUAR explained, partially, by their fundamentals.

\begin{tabular}{|c|c|c|c|c|c|c|c|c|c|c|c|}
\hline & & & & & & $\sigma_{a}$ & & & & & \\
\hline & 33.35 & & & & & & & & & & \\
\hline & $\%$ & $14 \%$ & $20 \%$ & $30 \%$ & $40 \%$ & $50 \%$ & $60 \%$ & $70 \%$ & $80 \%$ & $90 \%$ & $100 \%$ \\
\hline & 1 & $0.00 \%$ & $0.06 \%$ & $1.90 \%$ & $7.14 \%$ & $14.28 \%$ & $22.16 \%$ & $30.18 \%$ & $37.94 \%$ & $45.19 \%$ & $51.79 \%$ \\
\hline $\mathrm{T}$ & 5 & $2.01 \%$ & $9.43 \%$ & $26.68 \%$ & $43.79 \%$ & $57.93 \%$ & $68.80 \%$ & $76.93 \%$ & $82.97 \%$ & $87.45 \%$ & $90.77 \%$ \\
\hline & 10 & $8.06 \%$ & $22.19 \%$ & $46.34 \%$ & $64.61 \%$ & $76.91 \%$ & $84.98 \%$ & $90.27 \%$ & $93.73 \%$ & $95.99 \%$ & $97.46 \%$ \\
\hline
\end{tabular}

Table 12. YPF default probability sensitivity related to asset volatility and temporal horizon under the barrier option model. Source: Own elaboration.

\begin{tabular}{|c|c|c|c|c|c|c|c|c|c|c|c|}
\hline \multicolumn{12}{|c|}{$\sigma_{a}$} \\
\hline \multirow{4}{*}{$\mathrm{T}$} & $0.00001 \%$ & $14 \%$ & $20 \%$ & $30 \%$ & $40 \%$ & $50 \%$ & $60 \%$ & $70 \%$ & $80 \%$ & $90 \%$ & $100 \%$ \\
\hline & 1 & $0.00 \%$ & $0.00 \%$ & $0.00 \%$ & $0.00 \%$ & $0.00 \%$ & $0.00 \%$ & $0.03 \%$ & $0.18 \%$ & $0.64 \%$ & $1.65 \%$ \\
\hline & 5 & $0.00 \%$ & $0.00 \%$ & $0.01 \%$ & $0.45 \%$ & $3.19 \%$ & $9.81 \%$ & $19.81 \%$ & $31.56 \%$ & $43.48 \%$ & $54.53 \%$ \\
\hline & 10 & $0.00 \%$ & $0.00 \%$ & $0.59 \%$ & $6.00 \%$ & $18.74 \%$ & $35.31 \%$ & $51.59 \%$ & $65.38 \%$ & $76.09 \%$ & $83.95 \%$ \\
\hline
\end{tabular}

Table 13. ALUAR default probability sensitivity related to asset volatility and temporal horizon under the barrier option model. Source: Own elaboration. 
On both firms, barrier option obtains growing default probabilities as volatility gets higher (Figures 6 and 7). This is contrary to traditional model which ceases while having considered risk (Figures 4 and 5). Nonetheless, YPF presents a concave-shaped curve and decreasing default probability as volatility increases. On the contrary, ALUAR presents a convex-shaped curve, reverting the growing rate, with a sign change when volatility $>90 \%$, as it is observed on Figures 6-9.

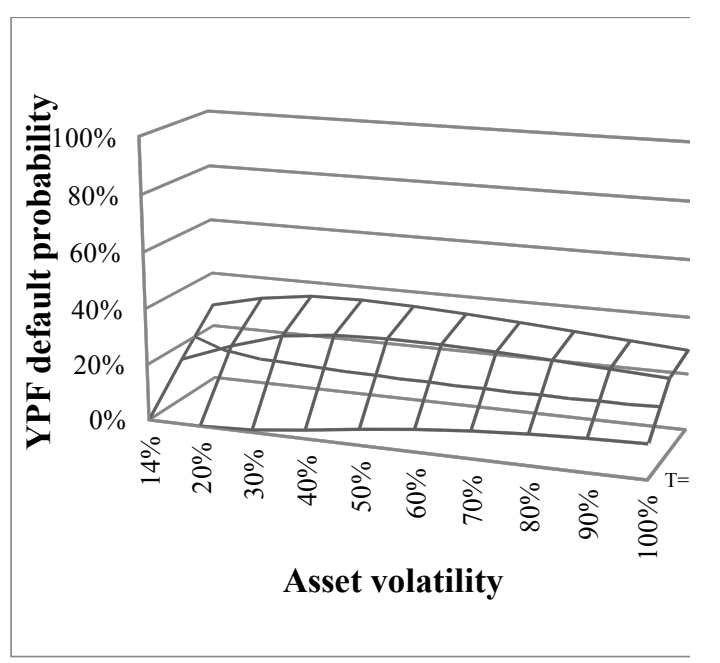

Figure 4. YPF default probability related to asset volatility and temporal related to asset volatility and temporal horizon under the traditional option model. horizon under the traditional option model. Source: Own elaboration.

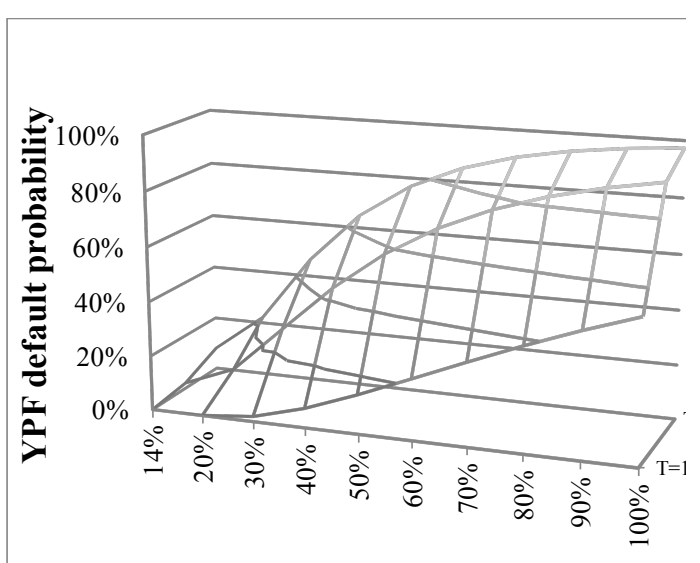

Asset volatility

Figure 6. YPF default probability related to asset volatility and temporal related to asset volatility and temporal horizon under the exotic option model. horizon under the exotic option model. Source: Own elaboration.

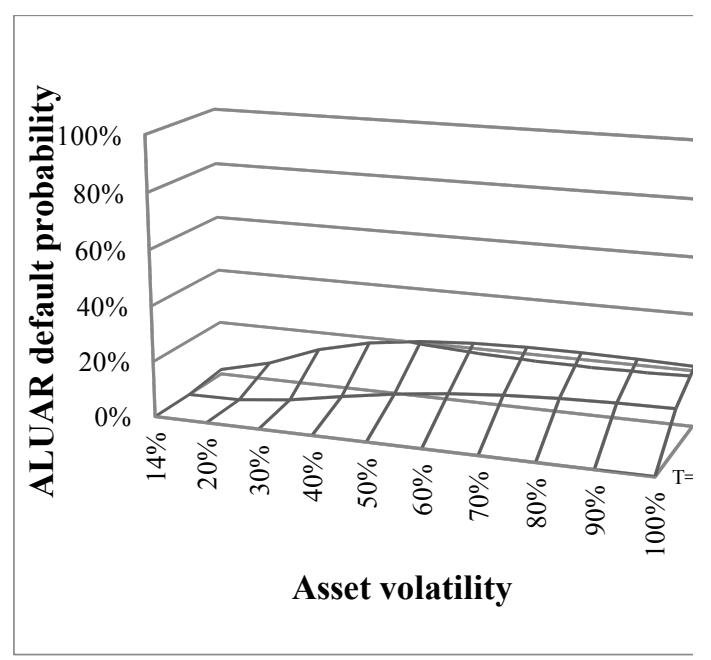

Figure 5. ALUAR default probability Source: Own elaboration.

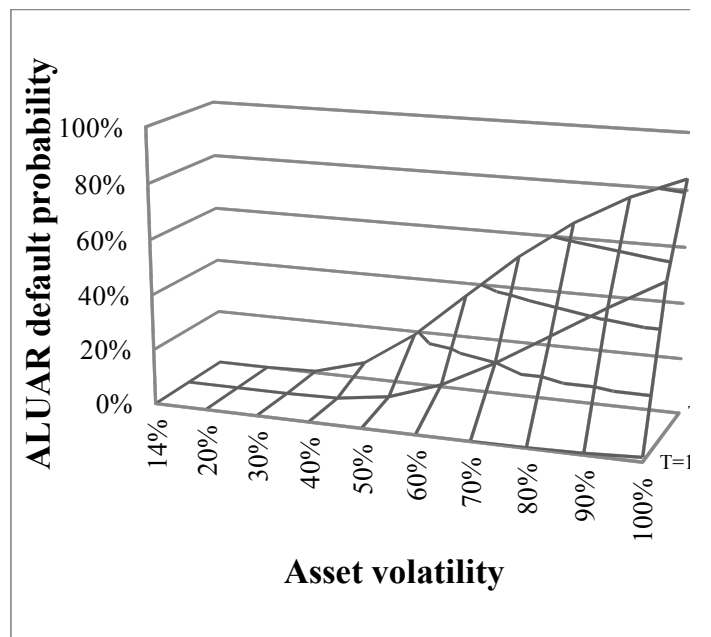

Figure 7. ALUAR default probability Source: Own elaboration. 


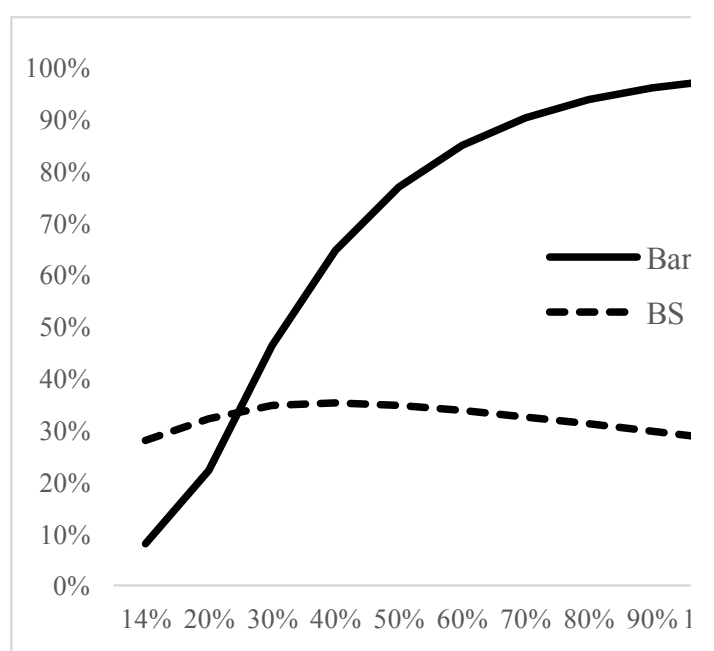

Figure 8. YPF default probability related to asset volatility and temporal horizon under the traditional (BlackScholes) and exotic (Barrier) option model. Source: Own elaboration.

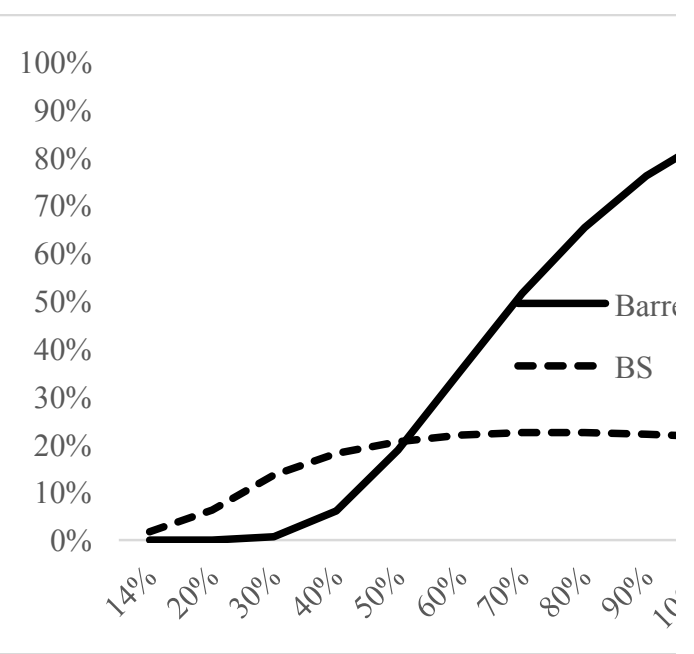

Figure 9. ALUAR default probability related to asset volatility and temporal horizon under the traditional (BlackScholes) and exotic (Barrier) option model. Source: Own elaboration.

Finally, Figure 10 contrasts different behavior between YPF and ALUAR default curves.

The former presents higher probabilities but with a strictly growing behavior with a decreasing slope. The latter, presents a convex behavior but with growing marginal rates.

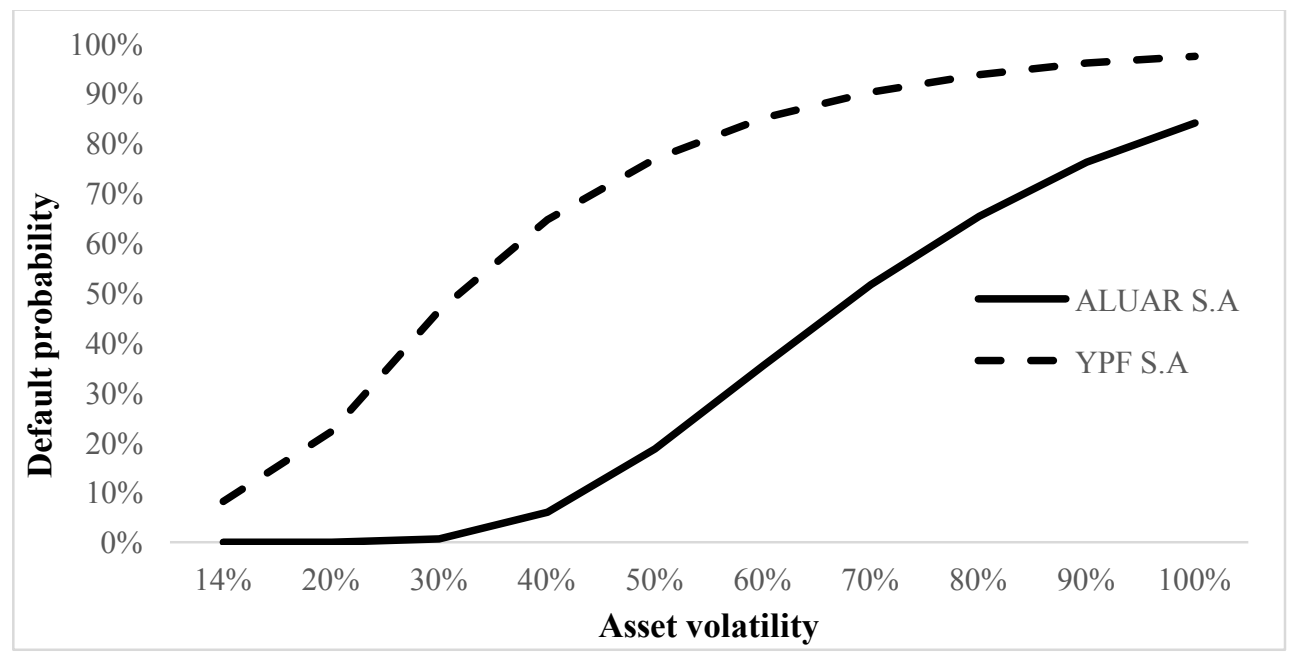

Figure 10. YPF vs ALUAR default probabilities related to asset volatility. Source: Own elaboration. 


\section{DISCUSSION}

Results obtained on the hypothetical case show how the proposed model adjusts better to business logic. This occurs because volatility increments impact negatively on shareholders' equity (Table 3). Asset volatility sensitivity analysis and time horizon supports this previous comment. For particular risks level where there are high probabilities that firm asset is below the critical debt level (barrier), default probabilities rise and shareholders' value diminishes (Tables $4 \& 5$ ). It must be highlighted that applying this model meant working with a naïve version based on its effectiveness according to Bharath and Shumay (2008). On this version, we suppose that asset value comes after assuming that capital market value (E) is represented by its market capitalization. Also, growth rate $(\mu)$ is given by the firm return on assets (ROA), and asset volatility $\sigma_{\mathrm{A}}$ comes after unleveraging asset price volatility. Studied cases related to ALUAR and YPF get to similar conclusions related to the effectiveness of comparing capital value to an exotic barrier option (Tables 13 \& 14). It is important to recall that these companies have different leverage ratios. According to Figure 10, YPF presents a growing concave-shaped curve with negative slope. In contrast, ALUAR show a convexshape curve with positive slope. Consequently, it is important to recognized this situation and get deeper into this field of study. Future research should aim to get full understanding empirically on default probability function while increasing business risk by business itself, by industry, and by region. Additionally, correlation between fundamentals and default probabilities should be determined. 


\section{CONCLUSIONS}

Comparing shareholders' equity to a call option brings a relative dynamic vision of value and default risk. Merton's model constitutes one the first contribution to the subject. However, it presents computational complexities on variable estimations in asset value and risk. Bharath and Shumay's naïve version simplifies the inputs without losing predictive power according to empirical evidence. Nonetheless, these models fail to adapt the traditional model related to a simple call option where volatility has a positive relationship with price. This could lead to situations where managers incorporate risky projects into the firm portfolio and, eventually, destroying shareholders' wealth.

The proposed model carries the advantage of estimating unobservable variables straight from the market such as market value and asset risk in a very simple manner. Moreover, while adopting the barrier option structure, it adjusts better to business reality where it is incorrect to assume that volatility rise impacts positively on value and default probability. The developed model achieves this objective and becomes a prospective tool to support information in business decision making. 


\section{REFERENCES}

Altman, E. (1968). Financial ratios, discriminant analysis and the predicition of corporate bankruptcy. Journal of Finance, 4, 589-609.

Altmant, E. (1993). Corporate Financial Distress and Bankrutpcy (Second ed.). New York, United State: Wiley Finance.

Altmant, E-Kishore, M. (1996). Almost everything you wanted to know about recoveries on default bonds. Financial Analyst Journal(52), 57-64.

Bharath, S-Shumay T. (2008). Forescasting Default with the Merton Distance to Default Model. Review of Finance Studies, 21, 1339-1369.

Black, F., \& Scholes, M. (1972, Mayo). The Valuation of Options Contracts and a Test of Market Efficiency. Journal of Finance, 399-418.

Black, F., \& Scholes, M. (1973, Mayo-Junio). The Pricing of Options and Corporate Liabilities. Journal of Political Economy, 637-659.

Brockman, P-Turtle, H. (2003). A Barrier Option Framework for Corporate Security Valuation. Journal of Financial Economics, 67, 511-529.

Chen, W-So L. (2014). Validation of the Merton Distance to the Default Model under Ambiguity. Journal of Risk and Financial Management , 7, 13-27.

Crosbie, P-Bohn J. (2002). Modeling defaukl risk. San Francisco, United State: KMV Corporation.

Daouk, H-Ng D. (2011). Is unlevered firm volatility asymmetric? Journal of Empirical Finance(18), 634-651.

Haug Gaarder, E. (2007). Derivatives: Models ond Models (1 ed.). Chichester : John Wiley \& Sons.

Hillegeist, S-Keating, E-Cram, D-Lundstedt, K. (2004). Assesing the probability of bankruptcy. Review of Accounting Studies(9), 5-34.

Hull, J. (2005). Futures, Options and other Derivatives (5 ed.). New Jersey: Prentice Hall.

Merton, R. (1973, Primavera). The Theory of Rational Options Princing. Bell Journal of Economics and Management Science, 141-183.

Merton, R. (1974). On the Pricing of Corporate Debt: The Risk Structure of Interest Rates. Journal of Finance, 29, 449-470.

Nielsen, L. (1992, 10). Undestanding N(d1) and N(d2): Risk adjusted probabilities in the Black-Scholes model. working paper, 1-16. Retrieved 11 20, 2014, from http://www.ltnielsen.com/wp-content/uploads/Understanding.pdf 
Reiz, A-Perlich C. (2007). A Market-Based Framework of Bankruptcy Prediction. Journal of Financial Stability, 3(2), 85-131.

Schwert, W. (1989). Why do stock market volatility chang ove time? Journal of Finance, $44,1115-1153$.

Vasicek, O. (2001). EDF credit measure and corporate bond pricing. San Francisco, United State: KMV corporation. 